Revista lus et Praxis, Año 20, № 1, 2014, pp. 67 - 90

ISSN 0717 - 2877

Universidad de Talca - Facultad de Ciencias Jurídicas y Sociales

"El acoso laboral:

tutela y prueba de la lesión de los derechos fundamentales"

Eduardo Caamaño Rojo - José Luis Ugarte Cataldo

Trabajo recibido el 21 de agosto de 2013 y aprobado el 26 de diciembre de 2013

\title{
El acoso laboral: tutela y prueba de la lesión de los derechos fundamentales*
}

\section{WORK HARASSMENT: DEFENSE AND PROOF OF DAMAGE TO BASIC RIGHTS}

\author{
Eduardo CaAmaño Rojo** \\ JosÉ LUIS UGARTE CATALDO***
}

\section{RESUMEN}

El presente estudio efectúa un análisis general de la reforma introducida al Código del Trabajo por la ley que tipifica y sanciona las conductas de acoso laboral, con el fin de presentar una visión dogmática unitaria que concilie las acciones tradicionales de despido y autodespido previstas por esta modificación legal, con la tutela de los derechos fundamentales en el ámbito de la empresa. Desde esta perspectiva, el estudio se concentra en la procedencia del proceso de tutela de derechos fundamentales para denunciar los casos de acoso laboral y en la prueba de la lesión de las garantías conculcadas por el acosador sobre la base de las reglas de la prueba indiciaria.

ABSTRACT

This study makes a general analysis of the reform to the Labour Code introduced by the law that penalizes and punishes work harassment, in order to give a single dogmatic view that combines both the traditional legal actions of dismissal and self-dismissal set forth by this reform, and the protection of basic rights in the business sphere. From this perspective, the study focuses on the appropriateness of the process of protection of basic rights in order to report cases of work harassment and on the proof of damage to rights violated by the harasser, according to the rules of circumstantial proof.

\section{Palabras Clave}

Acoso laboral, Mobbing, Derechos fundamentales, Prueba indiciaria

KEYWORDS

Work harassment, Mobbing, Basic rights, Circumstantial proof

* El presente artículo se ha desarrollado en el marco de la investigación asociada al Proyecto Fondecyt Regular N 1110457 "El acoso moral o mobbing y la acción de tutela en la nueva justicia laboral". Los autores agradecen a Fondecyt el financiamiento de esta investigación.

** Profesor de Derecho del Trabajo, Pontificia Universidad Católica de Valparaíso. Doctor en Derecho (Universidad de Colonia, Alemania). Correo electrónico: eduardo.caamano@ucv.cl.

*** Profesor de Derecho del Trabajo, Universidad Diego Portales. Doctor en Derecho (Universidad de Salamanca, España). Correo electrónico: jose.ugarte@udp.cl. 


\section{Introducción}

El 8 de agosto de 2012, a través de la publicación en el Diario Oficial de la ley $\mathrm{N}^{\circ} 20.607$, se puso término a un largo y lento debate legislativo sobre la necesidad de tipificar y sancionar los actos de acoso laboral. Este dilatado proceso de gestación de la ley mencionada, que la convierte en una especie de "elefante jurídico", aunque sin el peso ni la prestancia propia de un paquidermo, ha planteado una serie de críticas y dudas en nuestro medio, pues si bien la ley ha traído consigo algunos avances, no es menos cierto que esta reforma ha implicado también varios retrocesos en nuestro sistema de reconocimiento y tutela de los derechos fundamentales, como ocurrió también en su tiempo con la ley de acoso sexual, dado que el excesivo retardo en su tramitación no ha permitido una sinergia entre la respuesta normativa y los avances derivados de la reforma procesal laboral.

En efecto, y como lo ha puesto de manifiesto la doctrina ${ }^{1}$, es un aspecto positivo el que se haya tipificado jurídicamente el acoso laboral como un comportamiento atentatorio en contra de la dignidad de los trabajadores ${ }^{2}$ y, por lo mismo, lesivo de sus derechos fundamentales, con lo cual se viene a fortalecer la noción de "ciudadanía en la empresa" y a consolidar una nueva forma de entender las relaciones laborales, centrada en el respeto de los derechos esenciales de las personas. Asimismo, es valorable que la ley $\mathrm{N}^{\circ} 20.607$ haya incorporado a la legislación laboral un concepto de acoso que recoge las diversas clases o modalidades de este comportamiento lesivo de derechos fundamentales y que lo conciba como un ilícito objetivo o de resultado, siguiendo la senda iniciada por reformas anteriores como ocurrió con la sanción de los actos de discriminación y de acoso sexual.

Con todo, no es posible desconocer que la ley N $N^{\circ} 20.607$ presenta deficiencias al no haber explicitado la procedencia del proceso de tutela de derechos fundamentales como la vía natural de resguardo de las víctimas, como de hecho lo había reconocido la jurisprudencia posterior a la reforma procesal laboral de 2008. De igual manera, la reforma incluye vías tradicionales de sanción para el acoso laboral que no se condicen con un sistema coherente de reconocimiento y resguardo de las garantías constitucionales en el trabajo, como es el despido por una causal de caducidad del artículo 160 del Código del Trabajo (en ade-

\footnotetext{
1 Véase: López PerÁn (2012), p. 203 y ss.; Caamaño Rojo (2013), p. 65 y ss.

2 Un esquema similar asume el Estatuto de los Trabajadores en España, el cual dispone en su artículo 4.2.e) que las personas trabajadoras tienen derecho "al respeto de su intimidad y a la consideración debida a su dignidad, comprendida la protección frente al acoso por razón de origen racial o étnico, religión o convicciones, discapacidad, edad u orientación sexual, y frente al acoso sexual y al acoso por razón de sexo".
} 
lante CdT). Por cierto, si bien un comportamiento de acoso laboral implica una conducta grave que puede el empleador reprochar despidiendo al trabajador acosador, Ilama la atención que la reforma opte por incorporar esta causal en el $N^{\circ} 1$ del artículo 160, que es la de más difícil establecimiento, con lo cual torna dificultoso el cumplimiento del objetivo sancionador, sobre todo, al no haberse establecido mecanismos de prevención al interior de la empresa, como sí se hizo con la reforma que sancionó el acoso sexual.

A su vez, como si lo anterior no fuera suficiente, la ley No 20.607 reconoce la procedencia del autodespido de las víctimas, lo que en principio no es nuevo, pues era una vía ya utilizada antes de esta reforma, pero que hoy se ve completamente complejizada al tener que invocarse y establecerse en un juicio ordinario conforme al numeral $1^{\circ}$ del artículo 160, lo que resultará en la gran mayoría de los casos una operación de tipo "kamikaze" para las víctimas, por las dificultades probatorias que el acoso laboral o mobbing conlleva si se carece de mecanismos que alivianen esta carga, como sí se prevé para el procedimiento de tutela.

Por lo antes expuesto, este artículo desea poner de manifiesto la procedencia y vigencia indubitada del procedimiento de tutela de derechos fundamentales como una alternativa eficiente de resguardo de las víctimas del acoso laboral vertical, esto es, de aquel en que el empleador o sus representantes directos son responsables y, en particular, valorizar el rol de la prueba indiciaria reconocida por el artículo 493 del CdT para el establecimiento de los hechos y comportamientos configurativos del acoso laboral durante la vigencia de la relación laboral.

\section{El acoso laboral o mobbing y su tipificación en el Código del Trabajo}

Como es sabido, el acoso laboral o mobbing puede encontrar, por la particular configuración de la empresa y de las relaciones laborales subordinadas, un terreno fértil para su desarrollo. Por lo mismo, ya en la década de 1980 estas graves repercusiones del mobbing fueron puestas de manifiesto por Heinz Leymann ${ }^{3}$.

A partir de los estudios de Leymann se empieza a tomar conciencia acerca de la necesidad de adoptar medidas para enfrentar estos casos de hostigamiento en los lugares de trabajo, puesto que el mobbing afecta directamente la dignidad y múltiples derechos fundamentales de las personas acosadas. Se comienza a

\footnotetext{
3 Leymann, pionero en el estudio de estos comportamientos de acoso, llegó a sostener que: "En las sociedades de nuestro mundo occidental altamente industrializado, el lugar de trabajo constituye el último campo de batalla en el cual una persona puede matar a otra sin ningún riesgo de llegar a ser procesada ante un tribunal". Citado por PIÑUEL (2005), p. 19.
} 
producir así una interesante interrelación entre la Sicología y el Derecho del Trabajo $^{4}$, pues es la primera disciplina la que comienza a analizar la configuración, las causas y los efectos del acoso moral en las víctimas, mientras que la segunda será la que en la gran mayoría de los países asumirá la tarea de establecer mecanismos de resguardo y sanción, ya sea sobre la base del sistema general de protección de los derechos laborales, o bien, mediante reformas legales que se hacen cargo de las particularidades del mobbing. ${ }^{5}$

Ahora bien, la noción mobbing ${ }^{6}$ viene del verbo inglés to mob que significa atacar, acosar u hostigar, y comienza a perfilarse académicamente a partir de la década de 1960, como resultado de los estudios sobre la agresividad animal realizados por el profesor austríaco Konrad Lorenz. Estas investigaciones le permitieron advertir ciertas inquietantes similitudes con el comportamiento humano al interior de sus organizaciones, tales como el ataque de un grupo de individuos débiles de una especie contra otro más fuerte, o bien, el ataque por parte de un grupo contra un tercero ajeno a él. Estos resultados contribuyeron a acuñar el término mobbing y definirlo como: "el ataque de una coalición de miembros débiles de una misma especie contra un individuo más fuerte; o el de la mayoría de ellos contra un individuo distinto por alguna diferencia, defecto o rasgo significativo" ${ }^{\prime 7}$.

Más tarde, será el psicólogo sueco Heinz Leymann quien aplique el término mobbing a la Sicología laboral, definiéndolo como aquella: "Situación en la que una persona ejerce una violencia psicológica extrema, de forma sistemática y recurrente y durante un tiempo prolongado sobre otra persona o personas en el lugar de trabajo con la finalidad de destruir las redes de comunicación de la víctima o víctimas, destruir su reputación, perturbar el ejercicio de sus labores y lograr que finalmente esa persona o personas acaben abandonando el lugar de trabajo"s.

A partir de esta definición, Leymann ilustra el fenómeno señalando que el mobbing en la vida laboral conlleva una comunicación hostil y desprovista de ética que es administrada de manera sistemática por uno o unos pocos individuos, principalmente, contra un único individuo, quien a consecuencia de

4 Sobre la materia: Ugarte Cataldo (2012), pp. 221 y ss.

5 Excepcionalmente, algunos países han pretendido sancionar los casos de mobbing por la vía penal. Este es el caso, por ejemplo, de España, cuyo Código Penal en su artículo 173 dispone que: "(...) los que, en el ámbito de cualquier relación laboral o funcionarial y prevaleciéndose de su relación de superioridad, realicen contra otro de forma reiterada actos hostiles o humillantes que, sin Ilegar a constituir trato degradante, supongan grave acoso contra la víctima".

6 Otros términos para referirse al mobbing son: terror psicológico, acoso moral, violencia psicológica en el lugar de trabajo, hostigamiento psicológico, bullying laboral, abuso emocional en el trabajo. En este sentido: EsCARTín et al. (2012), p. 17.

7 En detalle: Abajo Olivares (2004), pp. 16-17.

8 Leymann (1996). 
esto, es lanzado a una situación de abandono e indefensión que induce a que continúe el comportamiento de acoso. Según Leymann, estas acciones deben ocurrir muy frecuentemente (por lo menos una vez por semana) y a lo largo de un periodo de tiempo (al menos de 6 meses). De esta manera, debido a la alta frecuencia y duración de la hostilidad, el maltrato resulta en una considerable miseria mental, sicosomática y social ${ }^{9}$.

Como lo pone de manifiesto Marie-France Hirigoyen ${ }^{10}$, sea cual sea la definición final, el acoso laboral es una violencia en pequeñas dosis, que no se advierte y que, sin embargo, es muy destructiva. En otros términos, dicho ataque, tomado por separado, no es realmente grave, sino que es el efecto acumulativo de microtraumatismos frecuentes y repetidos lo que constituye la agresión ${ }^{11}$.

Como se verá más adelante, estas apreciaciones generales efectuadas por Leymann constituirán la base a partir de la cual se irá precisando la noción de mobbing y sus elementos, como a su vez, explicarán las diversas modalidades que puede asumir este comportamiento de hostigamiento en el ámbito laboral sancionado luego por el Derecho ${ }^{12}$. Esta fuerte incidencia de la Sicología se explica, en algunos casos, porque el legislador la tuvo en cuenta al momento de legislar, o bien, porque en la recepción judicial ${ }^{13}$ de la noción de mobbing se han utilizado las nociones provenientes de dicha disciplina ${ }^{14}$.

En el caso de la ley $N^{\circ} 20.607$, su historia muestra cómo siempre fueron frecuentes las remisiones a los estudios de la Sicología sobre el mobbing. Esto ha redundado en que el concepto de acoso laboral aprobado mantenga algunas reminiscencias de esa disciplina, lo que no siempre es coherente con la forma en que el Derecho del Trabajo asume la tutela de los derechos fundamentales ${ }^{15}$.

\footnotetext{
9 Leymann (1996).

${ }^{10}$ HiRigoren (2001), p. 19. Esta autora define el acoso moral en el trabajo como "toda conducta abusiva (gesto, palabra, comportamiento, actitud...) que atenta, por su repetición o sistematización, contra la dignidad o la integridad psíquica o física de una persona, poniendo en peligro su empleo o degradando el ambiente de trabajo".

11 Por esta razón, el estrés derivado del exceso de trabajo, una amonestación del jefe directo, críticas aisladas, o bien, las jornadas de trabajo extensas o la prestación de servicios en precarias condiciones laborales no configuran supuestos de acoso moral. Véase: Bosqued LoReNTE (2005), pp. 29-30.

${ }^{12}$ De hecho, las referencias a los estudios de Leymann forman parte de las consideraciones teóricas que dieron sustento al proyecto que sirve de base a la Ley $N^{\circ} 20.607$, presentado por los diputados Ximena Vidal, Adriana Muñoz y Fidel Espinoza. Véase: Historia de la Ley $N^{\circ} 20.607$, p. 6, documento disponible en www.bcn.cl.

${ }^{13}$ Véase: CaAmaño Rojo (2011), p. 215.

${ }^{14}$ Gamonal Contreras y Ugarte Cataldo (2012), p. 27.

${ }^{15}$ En efecto, "cada disciplina parece tener su propio afán. En rigor, en la Psicología el problema parece dominar la perspectiva del daño síquico de la víctima, pero para el derecho la cuestión parece distinta:
} 


\subsection{El concepto legal de acoso laboral}

En la actualidad, el nuevo texto del artículo $2^{\circ}$ inciso $2^{\circ}$ del $\mathrm{CdT}$, en su frase $3^{\text {a }}$, establece que: "Asimismo, es contrario a la dignidad de la persona el acoso laboral, entendiéndose por tal toda conducta que constituya agresión u hostigamiento reiterados, ejercida por el empleador o por uno o más trabajadores, en contra de otro u otros trabajadores, por cualquier medio, y que tenga como resultado para el o los afectados su menoscabo, maltrato o humillación, o bien que amenace o perjudique su situación laboral o sus oportunidades en el empleo".

Una primera aproximación al concepto legal citado, evidencia que el acoso laboral es incompatible con el respeto a la dignidad humana, asumiéndose así una visión coherente con el rechazo de otras conductas que lesionan derechos fundamentales, como es el caso del acoso sexual. Con todo, no se puede perder de vista que el acoso laboral no sólo afecta a la dignidad, sino que puede lesionar a una pluralidad de derechos fundamentales de la víctima. De allí su reproche jurídico y su sanción ${ }^{16}$.

Según lo ha puesto de manifiesto la Dirección del Trabajo ${ }^{17}$, el análisis del precepto antes transcrito permite inferir que la intención del legislador ha sido sancionar el acoso laboral ejercido en las condiciones previstas en la nueva normativa como contrario a la dignidad de la persona, por tratarse de una conducta ilícita, que lesiona diversos bienes jurídicos que derivan de dicho derecho, tales como la integridad física y psíquica y la igualdad de oportunidades. De esta forma, el fundamento de su sanción es el respeto y promoción de los derechos fundamentales de las personas en el ámbito de su trabajo, resguardados por la Constitución y las leyes.

Ahora bien, a partir del análisis del concepto legal de acoso laboral, se puede sostener que éste se estructura sobre la base de los siguientes elementos ${ }^{18}$ :

a) Sujeto agresor: el artículo $2^{\circ}$ inciso $2^{\circ}$ del CdT es claro al establecer que el sujeto agresor en la nueva tipificación del acoso moral puede ser tanto el empleador, como el trabajador. De esta manera, se hace cargo de la principal

la afectación de determinados derechos fundamentales de la víctima como son la integridad síquica, la honra, la privacidad y la no discriminación". En este sentido, Ugarte Cataldo (2012), p. 229.

${ }^{16}$ De acuerdo con la Dirección del Trabajo, los derechos fundamentales más lesionados con ocasión del acoso laboral son: el derecho a la vida, a la integridad física y psíquica, al respeto y protección a la vida privada y a la honra de la persona y su familia, la inviolabilidad de toda forma de comunicación privada y el derecho a la no discriminación. Sobre la materia: ROMANIK FONCEA (2011), p. 38 (texto disponible en www.dt.gob.cl).

17 Dictamen No 3519/034, de fecha 9 de agosto de 2012.

${ }^{18}$ En igual sentido: López Perán (2012), pp. 208-210. 
distinción referida a las clases de acoso laboral, la que, en atención al agresor, distingue entre "acoso vertical"19, caracterizado por una conducta de hostigamiento proveniente del empleador y el "acoso horizontal", en el que uno o más trabajadores se convierten en los hostigadores de otro trabajador ${ }^{20}$.

Por otra parte, teniendo en consideración la amplitud de la norma en relación con la referencia a los sujetos, cabe concluir que en Chile también tendrían un reconocimiento los casos de "acoso laboral mixto". En este supuesto, el acoso comienza como horizontal, vale decir, el agresor es uno o varios de los compañeros de trabajo de la víctima, pero en un momento posterior, toma conocimiento de la situación la jefatura o el empleador y, en vez de intervenir en favor de la víctima, no adoptan ninguna medida para solucionar la situación. En estos casos existe claramente una omisión negligente por parte del empleador, sin perjuicio de que puedan presentarse también situaciones de hostigamiento directo por su parte. Por lo tanto, se configura una situación de complicidad entre todos los agresores. No obstante, es posible a su vez que el acoso laboral mixto tenga lugar a la inversa, esto es, que comience como un tipo de mobbing vertical descendente, para ver sumado luego el comportamiento hostil de uno o más trabajadores de similar jerarquía de la víctima ${ }^{21}$.

b) Conducta de agresión u hostigamiento: tratándose de lo que podríamos llamar el "verbo rector" en la tipificación del acoso laboral en Chile, se debe

${ }^{19}$ El mobbing vertical podrá ser ascendente, cuando se genera la excepcional situación de que una o varias personas en una posición jerárquica inferior dentro de la estructura de la organización acosan a una persona que se encuentra en una posición superior. Esta situación se puede dar, por ejemplo, cuando un trabajador pasa a tener como subordinados a los que fueron sus colegas de trabajo. También ocurre cuando se incorpora a la organización una persona a un cargo directivo, y desconoce la organización o incorpora nuevos métodos de gestión que no son compartidos o aceptados por los subordinados. Por el contrario, el mobbing vertical descendente (Ilamado también bossing), de mayor ocurrencia, tiene lugar cuando un sujeto en una posición jerárquica superior (v. gr. empleador, jefe directo) hostiga moralmente a su subordinado o dependiente. En Chile, la mayoría de los casos de mobbing denunciados a los tribunales corresponden a hostigamientos realizados por el empleador con el fin de forzar la renuncia del trabajador, creando un ambiente hostil e insoportable que lleve al trabajador a poner término al contrato, ahorrándose así el empleador el despido y el pago de las indemnizaciones legales. En otros casos, las conductas de acoso son parte de la estrategia del empleador para facilitar el posterior despido de la víctima, en razón de la disminución de su rendimiento o la comisión de errores derivados del acoso del cual es objeto. Véase: Gamonal Contreras y Guidi Moggia (2010), p. 222.

${ }^{20} \mathrm{El}$ ataque puede deberse a numerosas causas: celos, envidia, competencia o problemas de tipo personal. Aquí el acosador busca entorpecer el trabajo de su colega o compañero de trabajo con el objetivo de deteriorar su imagen o carrera profesional; también puede llegar a atribuirse a sí mismo los méritos ajenos. Se señala que esta clase de mobbing puede presentarse, porque la víctima es considerada distinta al resto del grupo, ya sea por su sexo, orientación sexual, religión, etc., o bien, porque la víctima reviste un peligro para el agresor (ejemplo, aspiraciones de ascenso), por envidia o por un simple afán de hostigar. Véase: Gamonal Contreras y Prado López (2006), p. 23.

${ }^{21}$ Gamonal Contreras y Prado López (2006), pp. 24-25; Hirigoyen (2001), p. 101. 
destacar que el legislador lo ha identificado sobre la base de dos acciones: agredir u hostigar. Para los efectos de precisar el alcance de estos términos, la Dirección del Trabajo ha recurrido a la regla de interpretación gramatical del artículo 20 del Código Civil, por lo que ha atendido al sentido natural y obvio de las palabras conforme a su definición en el diccionario de la Real Academia de la Lengua Española. De acuerdo con esta regla, se concluye que "es posible inferir que el legislador ha concebido las conductas constitutivas de acoso laboral en términos amplios, en forma tal que permita considerar como tales todas aquellas conductas que impliquen una agresión física hacia el o los trabajadores afectados o que sean contrarias al derecho que les asiste, así como las molestias o burlas insistentes en su contra, además de la incitación a hacer algo, siempre que todas dichas conductas se ejerzan en forma reiterada, cualquiera sea el medio por el cual se someta a los afectados a tales agresiones u hostigamientos" ${ }^{\prime 22}$.

Por otra parte, en relación con este elemento se debe señalar que el concepto legal de acoso laboral reconoce que la conducta agresiva puede producirse "por cualquier medio", con lo cual el CdT asume un criterio amplio que permitirá dar cabida a las infinitas posibilidades por medio de las cuales una creatividad desquiciada, perversa, ambiciosa o envidiosa pudiera pretender canalizar su objetivo de perjudicar a su víctima. Así, entonces, más que la vía o medio (v. gr. dichos, gestos, comunicaciones escritas, etc.), ${ }^{23}$ lo importante será la agresión y el resultado lesivo de ésta en materia laboral, lo que deberá ser determinado caso a caso por los Tribunales.

c) Reiteración: con este elemento, el legislador ha puesto de manifiesto que el comportamiento agresivo implica una suerte de persecución hacia la víctima, vale decir, un acoso. Efectivamente, de conformidad con el sentido que tiene el término acosar para la Real Academia Española, éste supone perseguir sin dar tregua ni reposo ${ }^{24}$. Por consiguiente, ya la definición de la palabra acosar conlleva la idea de que se trata de comportamientos que se reiteran en el tiempo, excluyendo acciones aisladas o esporádicas, con lo cual se vislumbra una clara diferencia con el acoso sexual, el cual se puede configurar por una sola conducta del agresor ${ }^{25}$.

No obstante, Ilama la atención que con la exigencia de este elemento el CdT asume una posición relativamente rígida, que impediría calificar como casos de

22 Dictamen № 3519/034, de fecha 9 de agosto de 2012.

${ }^{23}$ Véase: HiRIGOYeN (2001), p. 19.

${ }^{24}$ Según el Diccionario de la Real Academia Española, acosar significa: "Perseguir, sin darle tregua ni reposo, a un animal o a una persona", www.rae.es.

25 Véase: CaAmaño Rojo et al. (2005), pp. 8 y ss.; Rubio de Medina (2011), p. 28. 
acoso laboral a aquellas agresiones que se verifiquen por un comportamiento único, con lo cual pareciera que se sigue una conceptualización del mobbing más cercana a la Sicología que al Derecho del Trabajo, perdiéndose de vista que lo que debiera interesar prioritariamente desde una perspectiva normativa es el resguardo efectivo de los derechos fundamentales. Es por lo anterior, que existen legislaciones en las que este elemento de reiteración de la agresión se flexibiliza. Este es el caso, por ejemplo, de Colombia, en donde el artículo 7 de la ley $N^{\circ} 1.010$ de 2006 establece que: "excepcionalmente un solo acto hostil bastará para acreditar el acoso laboral. La autoridad competente apreciará tal circunstancia, según la gravedad de la conducta denunciada y su capacidad de ofender por sí sola la dignidad humana, la vida e integridad física, la libertad sexual y demás derechos fundamentales" 26 .

Sin perjuicio de lo expuesto, la amplitud del término "reiterados" da un amplio espacio para que los Tribunales determinen de qué manera se cumple este elemento para poder entender configurado un acoso laboral, puesto que no todos estos actos tienen la misma característica de temporalidad.

d) Resultados: en relación con este elemento, el artículo $2^{\circ}$ inciso $2^{\circ}$ del CdT señala que el acoso laboral debe tener "como resultado para el o los afectados su menoscabo, maltrato o humillación, o bien, que amenace o perjudique su situación laboral o sus oportunidades en el empleo".

Según la Dirección del Trabajo ${ }^{27}$, las conductas que ocasionen menoscabo, maltrato o humillación al o los trabajadores afectados, deben entenderse como cualquier acto que cause mengua o descrédito en su honra o fama o que implique tratar mal de palabra u obra o que los hiera en su amor propio o en su dignidad, o bien, que amenacen o perjudiquen la situación laboral o las oportunidades de empleo de dichos afectados. Además, cabe destacar que, según este Servicio, con la expresión "o bien que amenace o perjudique su situación laboral o sus oportunidades en el empleo", el legislador ha entendido que la conducta de acoso laboral se configura no sólo cuando la acción del empleador o del o los trabajadores ocasiona un perjuicio o daño laboral directo en su situación al interior de la empresa, sino también cuando por la creación de un ambiente hostil y ofensivo del trabajo, se pone en riesgo su situación laboral u oportunidades en el empleo. Este sería el caso, por ejemplo, de la utilización del acoso laboral como un medio para inducir a que la víctima renuncie a su empleo, con lo cual perdería el reconocimiento de los derechos laborales aso-

\footnotetext{
${ }^{26}$ Este mismo criterio lo sigue el Estado de Québec en Canadá, en donde el artículo 81.18 de la Ley de Normas del Trabajo dispone que: “(...) una sola conducta grave puede también constituir acoso psicológico si supone un daño y produce efecto nocivo continuado por el trabajador". Véase: GAMONAL Contreras y Ugarte Cataldo (2012), pp. 29-31.

27 Dictamen № 3519/034, de fecha 9 de agosto de 2012.
} 
ciados a la antigüedad, en particular, la indemnización por años de servicio, o bien, para afectar derechos que se le reconocen a la víctima del acoso en razón de su estado o actividad, como ocurre con el fuero maternal o sindical.

Este criterio de la Dirección del Trabajo guarda entonces relación con lo sostenido en dictamen $N^{\circ} 1133 / 36$, de fecha 21 de marzo de 2005 sobre el sentido y alcance de la norma sobre acoso sexual, también incorporada en su oportunidad al artículo $2^{\circ}$ inciso $2^{\circ}$ del $\mathrm{CdT}$ y que fue concebida, en cuanto a los resultados exigidos para dar por establecidas tales acciones, en forma similar a aquellas calificadas como acoso laboral. En efecto, según dicho pronunciamiento: "La ley ha entendido, al utilizar la expresión 'amenacen o perjudiquen su situación laboral', que se configura la conducta de acoso sexual no sólo cuando la persona afectada sufre un perjuicio o daño laboral directo en su situación al interior de la empresa, sino que también cuando por la creación de un ambiente hostil y ofensivo de trabajo, se pone en riesgo su situación laboral u oportunidades en el empleo".

Los términos en que ha sido recogido el elemento del resultado lesivo en Chile no dejan de ser meritorios, pues con ello el CdT es más fiel a la idea de la protección de los derechos fundamentales en los lugares del trabajo y se aparta de las consideraciones más difusas de la Sicología que podrían obstaculizar el establecimiento del acoso laboral en sede judicial. Así, entonces, el CdT parte de la base que el resultado lesivo se relaciona con la afectación de uno o varios derechos fundamentales y no con un daño síquico en concreto, de modo tal que lo lesionado es un conjunto de bienes jurídicos protegidos que giran en torno a la dignidad del trabajador, tales como la honra, la privacidad o la no discriminación ${ }^{28}$.

Por lo antes expuesto, se puede sostener que el concepto legal de acoso laboral incorporado por la ley $N^{\circ} 20.607$ está dentro de los estándares generales que se pueden extraer de las legislaciones de otros países que han optado por sancionar expresamente el mobbing, pudiendo servir de base para el desarrollo de una jurisprudencia que contribuya a delimitarlo y a darle un contenido acorde con los hechos que deba conocer y resolver. Además, corrige las deficiencias de la definición original propuesta en el proyecto de ley, particularmente, en lo que se refería al elemento subjetivo, lo que habría significado levantar una barrera probatoria prácticamente infranqueable para la gran mayoría de las víctimas.

Con todo, no se puede desconocer que la incorporación de un concepto legal de acoso implica una limitación de los alcances de este comportamiento lesivo de derechos fundamentales, el que a partir de la entrada en vigencia de esta reforma deberá circunscribirse a los términos en los que ha sido concebido, por lo que, al menos desde esta perspectiva, le ha cerrado una puerta a su

${ }^{28}$ En este sentido: Gamonal Contreras y Ugarte Cataldo (2012), p. 33. 
determinación por la vía jurisprudencial, lo que había comenzado a insinuarse cada vez con mayor claridad en nuestro medio ${ }^{29}$.

No obstante, un aspecto destacable es que con la introducción de un concepto legal de acoso laboral, se visualiza la gravedad y el impacto que puede tener el mobbing en el ámbito de las relaciones laborales en cuanto ilícito pluriofensivo de derechos fundamentales. De igual manera, se puede sostener que la tipificación del acoso laboral podría llegar a ser un elemento disuasivo al haberse visibilizado y objetivado qué se entiende por mobbing en el ámbito laboral, por lo que resultará interesante y necesario en el futuro una evaluación del impacto efectivo que haya significado la reforma introducida por la ley $N^{\circ} 20.607$.

\section{La protección de las víctimas de acoso laboral a través del procedimiento de tutela}

Un tema que resulta sensible luego de la reforma experimentada por el CdT en esta materia, tiene que ver con el rol que en la actualidad tiene el procedimiento de tutela de derechos fundamentales para el resguardo de las víctimas de acoso laboral. Esto es así, dado que el texto de la Ley № 20.607 omite toda referencia al procedimiento de tutela, limitándose a modificar los artículos 160 No 1 y 171 del CdT.

Para dar una respuesta a esta interrogante desde una perspectiva que sea coherente con el actual sistema de reconocimiento y protección de los derechos fundamentales en Chile, cabe tener en consideración que antes de la tipificación del acoso laboral, los tribunales habían conocido y sancionado estos comportamientos sobre la base de las normas generales del $\mathrm{CdT}^{30}$.

En efecto, si bien la normativa contenida en el CdT no aludía hasta el año 2012 a la figura del acoso laboral, contiene disposiciones que servían indudablemente para sostener la antijuridicidad del mobbing. En este sentido, la norma más general es la contenida en el artículo $2^{\circ}$ inciso $1^{\circ}$ del CdT, conforme a la cual: "Las relaciones laborales deberán siempre fundarse en un trato compatible con la dignidad de la persona". Además, refuerza la idea del debido respeto a la dignidad de los trabajadores, la disposición contenida en el artículo 153 inciso $2^{\circ}$ del CdT, en materia de reglamento interno, según la cual: "Especialmente, se deberán estipular las normas que se deben observar para garantizar un ambiente laboral digno y de mutuo respeto entre los trabajadores". Este precepto tiene una

\footnotetext{
${ }^{29}$ Véase: CaAmaño Rojo (2011), pp. 228 y ss.

${ }^{30}$ Esta situación de reconocimiento del mobbing por la vía judicial o administrativa representa la regla general en el Derecho Comparado. Es lo que ocurre, por ejemplo, en países como Argentina, Uruguay, España, Venezuela, Suecia, Finlandia o Italia. Sobre la materia: Gamonal Contreras y Ugarte Cataldo (2012), p. 25.
} 
especial significación, pues impone un amplio deber al empleador para asumir una actitud positiva, de manera tal que el desarrollo cotidiano de las relaciones laborales en la empresa tenga lugar en un clima de respeto.

De esta manera, entonces, no podían ni pueden aún resultar indiferentes para el empleador situaciones de conflicto o tensión derivados de actos de hostigamiento -sexual o laboral- por lo que debe utilizar las potencialidades que le ofrece el reglamento interno para normar las obligaciones y prohibiciones a que deben sujetarse los trabajadores durante su vida y permanencia al interior de la empresa, con miras a materializar un ambiente laboral en el que prime el respeto. Lo interesante es que el artículo 153 inciso $2^{\circ}$ del $\mathrm{CdT}$, a pesar de su carácter esencialmente declarativo, abre las puertas para que los empleadores se conviertan en agentes activos para el cambio del tradicional modelo de gestión del personal, de corte esencialmente autoritario, por uno que ponga énfasis en el respeto y en la plena vigencia de los derechos fundamentales de los trabajadores.

Por otra parte, cabe tener en cuenta el artículo 184 del CdT, que consagra el deber general de protección del empleador y con el cual se coloca al empleador en una posición de garante de la vida y salud de los trabajadores ante los riesgos laborales, intensificando de esta manera la eficacia horizontal de la garantía del artículo $19 \mathrm{~N}^{\circ} 1$ de la Carta Fundamental. En efecto, en virtud del contrato de trabajo el empleador debe asumir la obligación de tomar todas las medidas necesarias para proteger eficazmente la vida y salud de los trabajadores, de lo que cabe colegir la obligación específica de mantener un ambiente laboral libre de acoso moral, pues este tipo de hostigamiento afecta no sólo la integridad física del trabajador, sino que el derecho a la salud en su globalidad ${ }^{31}$. Por consiguiente, es indudable que el mobbing representa un claro riesgo sicosocial, siendo éste uno de los principales peligros emergentes en las nuevas formas de organización laboral ${ }^{32}$.

Asimismo, cobró especial significación como fundamento normativo para sustentar la protección frente actos de acoso laboral la norma del artículo 485 del $\mathrm{CdT}^{33}$, con la cual comienza la regulación del procedimiento de tutela de

\footnotetext{
${ }^{31}$ Así lo reconoce la sentencia del Tribunal del Trabajo de Curicó de fecha 13 de noviembre de 2010, RIT T-8-2010, la que, conociendo de una denuncia por vulneración de derechos fundamentales derivada de actos de hostigamiento del empleador hacia el trabajador, sin calificar dicho comportamiento como mobbing o acoso laboral, lo estima como vulneratorio del artículo 184 del CdT, al haberse acreditado en juicio la afectación a la salud física y síquica del demandante.

32 En este sentido: Palavecino Cáceres (2004). Véase también: Mangarelli (2008), pp. 85-86.

${ }^{33}$ La relevancia jurídica del artículo 485 del CdT como fundamento para el resguardo judicial frente a actos de acoso moral laboral ha sido reconocida, por ejemplo, por la sentencia del Tribunal del Trabajo de Punta Arenas de fecha 28 de enero de 2011, RIT T-5-2010, al consignar en su considerando undécimo: "Que el procedimiento de tutela de garantías fundamentales resguarda y de alguna manera legitima, el concepto de ciudadanía en la empresa, que abarca la horizontalidad de derechos fundamentales y el principio de vinculación directa de los derechos constitucionales entre particulares y que, a su vez,
} 
derechos fundamentales y que en su inciso $1^{\circ}$, prescribe que: "El procedimiento contenido en este Párrafo se aplicará respecto de las cuestiones suscitadas en la relación laboral por aplicación de las normas laborales, que afecten los derechos fundamentales de los trabajadores ${ }^{\prime \prime 34}$. Con esta disposición, se viene a reconocer explícitamente a los trabajadores una acción para denunciar cualquier vulneración de sus derechos fundamentales en el ámbito laboral, correspondiendo a los jueces laborales la tarea de velar por su protección y eficacia.

En mérito de lo expuesto, cabe sostener que ninguna de las consideraciones precedentes ha cambiado de contenido o función luego de la dictación de la ley $\mathrm{N}^{\circ} 20.607$, por lo que la valoración y vigencia de la dignidad de la persona del trabajador, en general, y de sus derechos fundamentales inespecíficos, en particular, se mantiene incólume y, es más, se fortifica con el reproche jurídico otorgado a los actos de acoso laboral.

Por otra parte, la ley № 20.607 no establece ninguna limitación explícita al derecho de los trabajadores a denunciar comportamientos de acoso laboral y la vulneración de sus derechos fundamentales a través del procedimiento de tutela. Por el contrario, un estudio exhaustivo de la historia de esta ley permite constatar que durante su tramitación legislativa se puso de manifiesto el aporte que representaba el procedimiento de tutela y la necesidad de mantenerlo como una vía idónea para la protección de las víctimas. Así, por ejemplo, en el informe de la Comisión de Trabajo de la Cámara de Diputados de fecha 16 de octubre de 2007, se estableció que: "Otro aspecto de orden técnico a considerar, a juicio del Ejecutivo, es que las denuncias que se presenten por conductas de acoso laboral, al incidir en la vulneración de derechos fundamentales del trabajador, deberán, necesariamente, ser conocidas en el nuevo procedimiento laboral a través de las normas sobre tutela de derechos fundamentales, que implican un mejoramiento sustantivo de las condiciones probatorias para el trabajador y su pretensión" ${ }^{\prime \prime}$.

descansa sobre la base de los derechos civiles y políticos del trabajador como individuo o lo que la doctrina Ilama derechos inespecíficos, que son aquellos que sin ser netamente laborales se aplican a la relación de trabajo en cuanto son inherentes a la condición de ciudadano del trabajador y que son, por tanto, distintos de aquellos derechos propiamente laborales o derechos específicos, que en nuestra legislación son regulados por el Código del Trabajo. En tal marco, el procedimiento invocado se aplica respecto de la vulneración de derechos inespecíficos, cuando aquellos derechos resulten lesionados en el ejercicio de las facultades del empleador, ejercidas en forma arbitraria, desproporcionada o sin respeto del contenido esencial de la garantía tutelada".

${ }^{34}$ Por su parte, el artículo 485 inciso 3 del CdT prescribe que: "Se entenderá que los derechos y garantías a que se refieren los incisos anteriores resultan lesionados cuando el ejercicio de las facultades que la ley le reconoce al empleador limita el pleno ejercicio de aquéllas sin justificación suficiente, en forma arbitraria o desproporcionada, o sin respeto a su contenido esencial".

35 Historia de la ley $N^{0} 20.607$, p. 24. 
De igual manera, en el primer informe de la Comisión de Trabajo del Senado, de fecha 13 de octubre de 2008, se señaló que: "En lo relativo a los procedimientos tutelares, (...) esta materia quedará bajo el amparo del nuevo procedimiento de tutela de los derechos fundamentales del trabajador que contempla la reforma procesal laboral, la cual se está implementando gradualmente en nuestro país" 36 .

Por consiguiente, una interpretación sistemática y concordante con el principio pro homine debe llevar a sostener que el sistema jurídico laboral ofrece mecanismos alternativos y/o complementarios a favor de las víctimas de acoso laboral, sin que ello permita excluir por falta de mención expresa al procedimiento de tutela de derechos fundamentales, toda vez que conduciría a validar respuestas normativas que limitarían el resguardo de estas garantías, negando el acceso a la justicia de los trabajadores afectados.

Así, entonces, en un supuesto de acoso laboral de carácter vertical que es aquel que interesa a este estudio, el trabajador que es víctima de él podrá optar entre:

- denunciar de tutela por lesión de derechos fundamentales de acuerdo con las normas generales de los artículos 485 y siguientes del CdT;

- denunciar de tutela por causa de acoso laboral, fundado en la disposición del artículo 485 del CdT;

- autodespedirse de acuerdo con lo previsto por el artículo 171, en concordancia con el artículo $160 \mathrm{~N}^{\circ} 1$ letra f) del CdT.

En los acápites siguientes se analizará la positiva incidencia que posee el procedimiento de tutela de derechos fundamentales para canalizar de una manera efectiva las denuncias por vulneración de estas garantías como consecuencia del acoso laboral, ya sea que esto ocurra durante la vigencia de la relación laboral, o bien, con ocasión del despido, dado que la prueba indiciaria que consagra este procedimiento viene a ser la piedra angular de un sistema jurídico laboral que posibilite verdaderamente conocer y sancionar las vulneraciones de los derechos en el ámbito de la empresa.

\section{El procedimiento de tutela de los derechos fundamentales: la prueba indiciaria}

Desde la entrada en vigencia de la reforma procesal laboral en el país, el año $2008^{37}$, se hizo posible poner fin a las deficiencias de nuestro sistema jurí-

\footnotetext{
${ }^{36}$ Historia de la ley $N^{\circ} 20.607$, p. 77. Véase también páginas 90; 105-110 en el marco del segundo informe de la Comisión de trabajo del Senado, de fecha 8 de mayo de 2012, y página 118. En curso del debate parlamentario, queda de manifiesto que nunca se pensó en excluir el procedimiento de tutela, sino que, por el contrario. se refuerza su efectividad para proteger a las víctimas de acoso laboral.

${ }^{37}$ En detalle: Lanata Fuenzalida (2010).
} 
dico para el resguardo de los derechos fundamentales de los trabajadores en el ámbito de la empresa, pasando éstos a ser "tomados en serio" ${ }^{38}$.

En efecto, el procedimiento denominado de "tutela laboral", regulado entre los artículos 485 a 495 del CdT, ha posibilitado la real eficacia de los derechos fundamentales "inespecíficos" de los trabajadores, dentro de los cuales se encuentran varios de los derechos involucrados en el acoso laboral: integridad física y síquica, privacidad, honra y no discriminación en el trabajo.

Se trata de una acción procesal que permite ejercer los citados derechos fundamentales frente a eventuales lesiones por conductas empresariales que se produzcan durante o al término de la relación laboral. Dicha acción -que se tramita con arreglo al procedimiento de aplicación general- permite al juez del trabajo aplicar de modo directo los derechos fundamentales del trabajador.

Es, además, una acción que vino a hacerse cargo de gran parte de las falencias de la anterior legislación; se entregaron a los jueces del trabajo las atribuciones necesarias para conocer y sancionar las lesiones de derechos fundamentales, incluyendo mecanismos de resguardo y de reparación, y se consagraron reglas probatorias especiales ${ }^{39}$-la prueba de indicios del artículo 493- mediante las cuales se facilita a las víctimas el establecimiento de los hechos denunciados ${ }^{40}$.

De esta manera, la reforma procesal laboral abrió una puerta importante para que cualquier trabajador afectado en sus derechos fundamentales ${ }^{41}$, por ejemplo, por comportamientos de acoso laboral, pudiera efectuar una denuncia judicial en contra de su empleador sobre la base de lo previsto por el artículo 485, con la posibilidad de obtener, incluso, una indemnización por los perjuicios derivados de ese actuar lesivo ${ }^{42}$. En efecto, como lo plantea Ugarte ${ }^{43}$, el procedimiento de tutela viene a ser la traducción procesal de la idea de la eficacia horizontal de este tipo de derechos en las relaciones jurídicas entre

\footnotetext{
${ }^{38}$ Véase: Ugarte Cataldo (2007), pp. 61y ss.

39 Sobre la materia: Ugarte Cataldo (2009 a), pp. 215 y ss.

40 En detalle: Gamonal Contreras (2008); Ugarte Cataldo (2009 b). Sobre la acción de tutela de las víctimas de acoso laboral en España véase: Rodríguez Sanz de Galdeano (2011), pp. 111 y ss.; Molina NAVARRETE (2007), pp. 21y ss.

${ }^{41}$ El artículo 485 inciso 1 del CdT establece que: “El procedimiento contenido en este Párrafo se aplicará respecto de las cuestiones suscitadas en la relación laboral por aplicación de las normas laborales, que afecten los derechos fundamentales de los trabajadores, entendiéndose por éstos los consagrados en la Constitución Política de la República en su artículo 19, números $1^{\circ}$, inciso primero, siempre que su vulneración sea consecuencia directa de actos ocurridos en la relación laboral, $4^{\circ}, 5^{\circ}$, en lo relativo a la inviolabilidad de toda forma de comunicación privada, $6^{\circ}$, inciso primero, $12^{\circ}$, inciso primero, y $16^{\circ}$, en lo relativo a la libertad de trabajo, al derecho a su libre elección y a lo establecido en su inciso cuarto, cuando aquellos derechos resulten lesionados en el ejercicio de las facultades del empleador".

42 En detalle: Thauby de LA Torre (2012).

43 Ugarte Cataldo (2009 b), p. 23.
} 
privados y, en este particular caso, al interior del contrato de trabajo. Además, no sólo se trata de la eficacia horizontal de los derechos fundamentales entre particulares, sino de su eficacia inmediata, en cuanto la acción judicial se ejerce directamente por el trabajador en contra del otro particular involucrado en la relación laboral, vale decir, el empleador.

\subsection{Los elementos del acoso laboral: ¿qué se debe probar?}

Sin duda alguna, la introducción de la figura del acoso laboral en la legislación chilena constituye, en sí misma, una descarga importante para el trabajador que se enfrenta a un proceso de esta naturaleza, especialmente en países con una tradición legalista tan arraigada como el nuestro. En este sentido, la víctima podrá invocar la conducta lesiva contenida en la segunda parte del artículo $2^{\circ}$ inciso $2^{\circ}$ del $\mathrm{CdT}$, denunciando, con algo de comodidad, la genuina infracción a la ley laboral positiva.

No obstante, esta invocación dista de encontrarse liberada de prueba y es por ello que el legislador se ha ocupado de incluir en su definición, elementos que deberán ser acreditados en el proceso. De acuerdo con lo expresado en las líneas precedentes, algunos de estos factores han sido establecidos con un contenido suficientemente amplio, como para evitar circunscribir el mobbing a aquellas conductas que se presentan con mayor frecuencia en situaciones de acoso.

De este modo, la presencia de un sujeto agresor es imprescindible para acreditar la procedencia de un acoso vertical, horizontal o mixto y en este sentido, el trabajador será quien deba demostrar que la conducta proviene de su empleador o de otros trabajadores, o bien, que ambos agentes han concurrido, mediante acciones u omisiones, a propiciar el mobbing y la consecuente lesión de derechos fundamentales.

Por otra parte, la agresión u hostigamiento se transforma también en un elemento laxo dentro del concepto de acoso laboral puesto que, tal como se indicó, el propio artículo $2^{\circ}$ constituye una norma de apertura en cuanto a los medios que puedan ser utilizados para concretar la agresión. La prueba, en este caso, sólo se orienta a exponer el hostigamiento, careciendo de total relevancia la vía por la cual éste se haya ejercido.

Hasta ahora, los referidos elementos no constituyen una prueba en exceso gravosa para el denunciante; sin embargo, la exigencia de que la conducta ofensiva sea reiterada, finalmente estrecha el concepto de mobbing y le imprime el sello de la Sicología ${ }^{44}$, que, en cierta medida, aleja a la figura del Derecho del Trabajo y de la protección de los derechos del trabajador.

${ }^{44}$ Ugarte Cataldo (2012), pp. 225-227. 
En efecto, en la práctica jurisprudencial se aprecia la extraordinaria importancia que se le da a este componente y el efecto que genera es, con frecuencia, negativo, pues se condiciona la noción de acoso y las demandas son rechazadas por no demostrarse la reiteración de la agresión u hostigamiento. La consecuencia de que los tribunales eleven este elemento a la calidad de "esencial" es clara: al no configurarse la persistencia temporal de la agresión, el análisis de la lesión de los derechos fundamentales del trabajador, que es el verdaderamente relevante y que constituye el núcleo del acoso laboral, termina siendo minimizado ${ }^{45} \mathrm{O}$, peor aún, simplemente soslayado ${ }^{46}$.

Si bien es cierto, el acoso en el trabajo por regla general se presenta como un atentado continuo, ya sea éste permanente o sólo reiterado, también podría pensarse en ciertas hipótesis en que gestiones aisladas concreten el asedio, si éstas aparejan como consecuencia el elemento central del mobbing: que la conducta hostil vulnere derechos fundamentales de origen constitucional del trabajador, protegidos por la acción de tutela de los mismos en el CdT.

Una vez aceptado que la vía procesal para llevar adelante una acción por acoso laboral está dada por las normas de tutela de derechos fundamentales, cobra relevancia la concepción que se acepte de dicha figura, pues ella determinará el objeto principal de prueba en este proceso. Y en este sentido, el factor que articula el mobbing se relaciona con el resultado que produzca la agresión y que variará si se adopta una noción subjetiva u objetiva del mismo.

Una concepción subjetiva necesariamente conlleva aproximar la figura a la Sicología, contigüidad que se torna peligrosa en tanto exigirá del trabajador una prueba difícil de proporcionar en juicio: no sólo deberá acreditar la actitud consciente e intencional del sujeto denunciado de acosar a la víctima, sino que además será necesario demostrar la efectiva producción de un daño en su esfera sicofísica y el correspondiente vínculo causal entre el hecho y el perjuicio experimentado ${ }^{47}$.

\footnotetext{
${ }^{45}$ Hay situaciones en que, si bien se examina efectiva lesión de derechos fundamentales, la persistencia de la actuación denunciada constituye un antecedente tan importante en la fundamentación de las sentencias que, finalmente, inclina la decisión hacia el rechazo de la demanda. Corte de Apelaciones de Santiago, 26 de agosto de 2009, décima sala, número de ingreso 7553-08; Primer Juzgado de Letras del Trabajo de Santiago, RIT T-351-12, RUC 12-4-0025329-1, 22 de octubre de 2012.

${ }^{46}$ En este sentido se ha pronunciado la Corte Suprema, al rechazar un recurso de casación, señalando que la "característica esencial" del acoso laboral es la continuidad de tales actos y que éste no se configura por situaciones puntuales de agresión. Con esta declaración, confina el examen de la vulneración de derechos fundamentales: por el solo hecho de no verificarse la reiteración de la conducta, no se cumplirían los presupuestos de procedencia del mobbing y, por tanto, la acción se encuentra correctamente desechada por el juez de la instancia. Corte Suprema, rol 3939-09, 18 de agosto de 2009, cuarta sala, número identificador vLex: VLEX-64643656.

${ }^{47}$ Así se han pronunciado ciertas decisiones judiciales que, al exigir ambas pruebas, terminan por fusionar el acoso laboral con la producción de un daño moral, desechando la procedencia del mobbing por
} 
Por su parte, una concepción objetiva acerca el acoso laboral al Derecho del Trabajo y lo sitúa dentro de su ámbito de resguardo. El matiz jurídico en este caso, modifica el objeto principal de prueba en el proceso y lo traslada a la afectación de ciertos derechos fundamentales del trabajador ${ }^{48}$. De esta forma, para que determinados casos se consideren configurativos de acoso laboral, lo que deberá demostrarse en el juicio es la efectiva vulneración de estos derechos, sin que necesariamente la víctima haya acreditado un daño físico o sicológico como consecuencia de la conducta hostil.

Por cierto, no se desconoce la influencia de la Sicología en este ámbito, sin embargo, el cambio de disciplina amplía las posibilidades de un trabajador de obtener las medidas de reparación por el acoso, al generar un importante alivio probatorio. Y esta morigeración se incrementa gracias a las reglas establecidas para tramitar las acciones de tutela de derechos fundamentales: la prueba indiciaria produce una rebaja en el estándar de convicción, evitando desproteger al denunciante con exigencias probatorias desmedidas.

\subsection{La prueba indiciaria en el acoso laboral: ¿cómo se debe probar?}

Como se ha señalado en otras oportunidades ${ }^{49}$, la relativamente reciente modificación a la justicia laboral introdujo instituciones protectoras de los derechos del trabajador inéditas hasta ese momento. Y en este sentido, no sólo se consagró una nueva regulación sustantiva, sino que también se hizo hincapié en que ese resguardo fuese efectivo en términos adjetivos, con la finalidad de materializar las aspiraciones de sus usuarios.

La preocupación por tutelar con eficacia los derechos del trabajador, se demuestra en el énfasis puesto en la consideración de un vía procesal que permitiera consumar las declaraciones hechas en sede sustantiva ${ }^{50}$. Una importante manifestación de esta inquietud del legislador se plasmó en el procedimiento de tutela de derechos fundamentales, particularmente, en el artículo 493 del CdT, que señala: "Cuando de los antecedentes aportados por la parte denunciante resulten indicios suficientes de que se ha producido la vulneración de derechos

no acreditarse suficientemente el daño sicológico de la víctima. Corte de Apelaciones de Concepción, número de ingreso 3583-06, 20 de agosto de 2007.

${ }^{48}$ Ugarte Cataldo (2012), pp. 228-229.

49 Ugarte Cataldo (2009 a), p. 59.

${ }^{50}$ En este sentido, aun cuando se considera que las normas procesales constituyen reglas adjetivas y meramente instrumentales, es claro que ellas tienen valoración propia, dado que consisten en el instrumento necesario para establecer medios de protección que harán ciertas las normas sustantivas, proscribiendo la autotutela en el ejercicio práctico de las mismas. Álvaro de Oliveira (2008), pp. 176 y 177. 
fundamentales, corresponderá al denunciado explicar los fundamentos de las medidas adoptadas y de su proporcionalidad".

Tal como se desprende de la disposición transcrita, el CdT en ningún caso optó por eximir al sujeto activo de una acción de tutela de la carga de proporcionar antecedentes al proceso, orientados a acreditar su pretensión. Tampoco, como se ha pretendido, alteró la carga de la prueba, trasladándola directamente al denunciado e imponiéndole la acreditación de hechos negativos, como sería la no concurrencia de una situación de acoso laboral. Más bien, esta norma se acerca a una modificación en la carga material de la prueba, es decir, "la distribución del costo del hecho que ha quedado inciertamente determinado por los medios de fijación o de prueba que han operado en la etapa probatoria del procedimiento de tutela"151.

Tradicionalmente, sobre el demandante recae una pesada sanción si no logra acreditar sus aseveraciones y mantiene dudas sobre su efectiva ocurrencia. En tal sentido, corre el riesgo de sucumbir en el proceso, pues la falta de prueba le haría trasgredir su obligación de apoyar la búsqueda de la verdad, a la cual se habría comprometido una vez que se somete al mismo ${ }^{52}$. Por este motivo, el llamado "riesgo de la prueba", se transforma en un mecanismo abrumador para un denunciante de acoso laboral, quien regularmente no contará con medios de prueba directos para acreditar su acción. Es por ello que el artículo 493 diluye esta exigencia y la traspasa a la parte denunciada, quien deberá demostrar la necesidad y proporcionalidad de las medidas reprochadas, en el marco de la relación laboral.

En consecuencia, la carga de la prueba sigue recayendo sobre el trabajador que ha sido víctima de un acoso laboral; sin embargo, deberá encaminarse a demostrar que existen "indicios suficientes" de una lesión de derechos fundamentales, a través de conductas hostiles o agraviantes. Estos indicios, usualmente conocidos como prueba indirecta o circunstancial, corresponden, como se ha señalado, a "hechos que generen en el juez una sospecha razonable de que ha existido una conducta lesiva ${ }^{153}$ y técnicamente equivalen a aportar un "principio de prueba" al juicio, que será suficiente para dar por cumplida la labor probatoria del demandante ${ }^{54}$. Ha sido éste el sentido que, en general, se aprecia en las sentencias de acoso laboral. Ya sea que se acojan o rechacen demandas, se descarta la aportación de una prueba directa que determine fehacientemente la veracidad de los hechos que se denuncian o la

\footnotetext{
51 Ugarte Cataldo (2009 a), p. 220 y Ugarte Cataldo (2009 b), p. 44.

52 MeKKI (2013), pp. 19-20.

53 Ugarte Cataldo (2009 a), p. 223.

54 Ugarte Cataldo (2009 b), pp. 46-47.
} 
irrefutable procedencia de la causal del artículo $160 \mathrm{~N}^{\circ} 7$ del CdT, si se trata de un caso de despido indirecto ${ }^{55}$.

Por el contrario, salvo ciertas excepciones cada vez más aisladas ${ }^{56}$, la jurisprudencia ha entendido que el trabajador no se encuentra en una posición privilegiada que le permita introducir elementos probatorios categóricos y descarga su rigidez en el denunciado, quien deberá "explicar los fundamentos de las medidas adoptadas y de su proporcionalidad". De la redacción de la norma se desprende que el legislador tenía en vista las hipótesis de acoso laboral vertical o mixto, las que se podrán desvirtuar sólo mediante esta específica prueba liberatoria. Así, la ley laboral ha tomado en cuenta la disparidad de los litigantes y las evidentes dificultades que enfrenta el trabajador que invoca una situación de mobbing, y por ello ha puesto su severidad de cargo del empleador, quien se encuentra en la mejor posición para justificar la razonabilidad de su conducta ${ }^{57}$.

Esta disposición que, en rigor, constituye una regla de juicio que opera al momento de la deliberación y confección de la sentencia ${ }^{58}$, conceptualmente constituye una rebaja en el estándar de convicción del juez, que le permitirá dar por verificada una situación de acoso, con fundamento en indicios suficientes de la misma. Se trata en este caso de la aplicación de un juicio de razonabilidad, que se aleja de la "absoluta certeza", "plena prueba" o "íntima convicción". Con ello, el tribunal podrá acoger demandas de acoso laboral sin necesidad de alcanzar la comprobación directa y absoluta de los hechos denunciados, sino que le bastará advertir una "sospecha razonable" de que se ha producido una conducta lesiva de derechos fundamentales, para que ésta se estime acreditada.

En este sentido, el Derecho Laboral avanza en la protección del trabajador, toda vez que, a diferencia de la justicia civil e, incluso, de la reformada justicia de familia ${ }^{59}$, se consagra expresamente un estándar de convicción rebajado respecto de aquel litigante que se encuentra en una posición probatoria dis-

\footnotetext{
${ }^{55}$ En este sentido y declarando que no se trata de una verdadera inversión en la carga de la prueba, véase Corte de Apelaciones de Punta Arenas, número de ingreso 19-12, 2 de agosto de 2012; Primer Juzgado de Letras del Trabajo de Santiago, RIT T-351-12, RUC 12-4-0025329-1, 22 de octubre de 2012; Corte Suprema, número de ingreso 8798-10, 23 de junio de 2011, cuarta sala, número identificador v-Lex: VLEX-333768150; Corte de Apelaciones de Talca, número de ingreso 228-10, 10 de diciembre de 2010, segunda sala, número identificador v-Lex: VLEX-235907251.

${ }^{56}$ Corte de Apelaciones de Concepción, número de ingreso 640-08, 2 de septiembre de 2010.

${ }^{57}$ Corte de Apelaciones de Santiago, número de ingreso 9791-08, 6 de octubre de 2009, décima sala.

${ }^{58}$ UGarte Cataldo, José Luis (2009 a), pp. 220-221.

${ }^{59}$ Solamente se han detectado modificaciones a propósito de la incorporación de la reforma procesal penal, que considera un estándar de convicción más flexible que la íntima convicción. El artículo 340 del Código Procesal Penal consagra el nuevo estándar de prueba que regirá los procedimientos criminales y que se alcanza mediante una convicción formada "más allá de toda duda razonable".
} 
minuida. Gracias a esta consideración es que se aligera la importante carga que debe enfrentar quien ha sido víctima del mobbing y en consecuencia, el Derecho del Trabajo hoy cumple con mayor efectividad uno de sus principales cometidos: dar vigencia a la noción de ciudadanía en la empresa, a través del resguardo de los derechos fundamentales del trabajador.

\section{A modo de conclusión}

La incorporación de la figura del acoso laboral o mobbing en la legislación chilena, constituye en algún sentido un avance importante en la protección de los derechos fundamentales del trabajador. Aunque ya tempranamente la noción de ciudadanía en la empresa hizo grandes aportes en el incipiente reconocimiento y resguardo de sus derechos constitucionales inespecíficos, la incorporación del acoso laboral en el derecho escrito, no sólo describe una conducta ilícita en que puede incurrir un empleador o un trabajador en contra de otro, sino que simboliza una auténtica preocupación por su dignidad e integridad.

Pese a ello, y tal como se indicó desde las líneas iniciales, el legislador omitió referencias a la normativa procesal que la rige, no encontrándose indicación directa acerca de las reglas de juicio por las que se debieran tramitar causas de esta índole. No obstante, ello no constituye óbice para que dichas acciones aprovechen las ventajas que reporta la consecución del procedimiento de tutela de derechos fundamentales, que ha sido diseñado específicamente para hacer efectiva la declaración de protección del legislador en relación con dichos derechos.

De esta manera, con mayor o menor amplitud, la tipificación del mobbing determina las condiciones que concurren en la figura y que, en consecuencia, han de ser invocadas y acreditadas en un juicio. Por cierto, elementos como la existencia de un agente que realice la conducta abusiva, ya sea el empleador u otro trabajador, o los medios utilizados para materializarlo, no representan una dificultad relevante en términos de prueba.

Pero sí podría restringir la figura del acoso laboral, una aplicación extensiva del requisito de reiteración de la conducta hostil, condicionando el análisis de la afectación de derechos fundamentales a un plano secundario, o simplemente a ninguno. Y se detecta también una constricción del mobbing, en tanto se supedite la procedencia de la conducta lesiva, a la acreditación del daño experimentado por el trabajador o de la causal contenida en el artículo 160 $\mathrm{N}^{0} 1$ del $\mathrm{CdT}$, si este último hubiese invocado el despido indirecto.

Finalmente, el elemento central del acoso laboral -el acoso u hostigamiento que afecta derechos fundamentales del trabajador- podría, en principio, representar una excesiva carga probatoria para el denunciante. Tanto por el carácter encubierto de estas actitudes, como por la desproporción de las posiciones de 
las partes en un proceso, la tarea de acreditar los hechos denunciados se hace prácticamente imposible si no se consideran rebajas a esta carga.

Es por ello que el procedimiento de tutela se transforma en la vía adecuada para garantizar estos derechos: la rebaja del estándar probatorio, que elimina la necesidad de una convicción absoluta en el juez, beneficia la postura del denunciante. Así, sus aseveraciones deberán darse por demostradas con la prueba de indicios que revelen conductas lesivas de derechos fundamentales y cuya justificación o proporcionalidad no hayan logrado ser explicadas por el denunciado.

\section{Bibliografía CitADA}

Abajo Olivares, Javier (2004): Mobbing. Acoso psicológico en el ámbito laboral (Buenos Aires, Editorial Lexis Nexis - Depalma).

Álvaro de Oliveira, Carlos Alberto (2008): Teoría y práctica de la tutela jurisdiccional (Traducc. Juan José Monroy Palacios, Lima, Editorial Communitas).

Bosqued Lorente, Marisa (2005): Mobbing. Cómo prevenir y superar el acoso psicológico (Barcelona, Editorial Paidós).

Caamaño Rojo, Eduardo; Carvajal Godor, Gabriela; Jiménez Trejo, Patricio (2005):

El acoso sexual en la empresa. Análisis de la Ley Nº 20.005 (Santiago, Editorial Lexis Nexis).

CaAmaño Rojo, Eduardo (2011): "La noción de acoso moral o mobbing y su reconocimiento por la jurisprudencia en Chile", en: Revista de Derecho, Pontificia Universidad Católica de Valparaíso (Volumen XXVII, Semestre II), pp. 215-240.

CAAmaño Rojo, Eduardo (2013): “La sanción del acoso laboral: crónica de una mala ley con algunas buenas intenciones", en: Revista Laboral Chilena (No 214), pp. 65-77.

Escartín, Jordi; Rodríguez-Carballeira, Álvaro; Zapf, Dieter (2012): Mobbing: Acoso psicológico en el trabajo (Madrid, Editorial Síntesis).

Gamonal Contreras, Sergio; Prado López, Pamela (2006): El mobbing o acoso moral (Santiago, Editorial Lexis Nexis).

Gamonal Contreras, Sergio (2008): El procedimiento de tutela de derechos laborales (Santiago, Editorial Legal Publishing).

Gamonal Contreras, Sergio, Guidi Moggia, Caterina (2010): Manual de contrato de trabajo (Santiago, Editorial Abeledo Perrot).

Gamonal Contreras, Sergio; Ugarte Cataldo, José luis (2012): "Acoso sexual y moral en el lugar de trabajo", en: Presente y futuro del Derecho del Trabajo y de la Seguridad Social, Documentos de XX Congreso Mundial de Derecho del Trabajo y de la Seguridad Social (Santiago, Editorial Abeledo Perrot-Thomson Reuters). 
HIRIGOYEN, Marie-France (2001): El acoso moral en el trabajo. Distinguir lo verdadero de lo falso (Barcelona, Ediciones Paidós).

Lanata Fuenzalida, Gabriela (2010): Manual de proceso laboral (Santiago, Editorial Abeledo Perrot).

Leymann, Heinz (1996): The Mobbing Encyclopedia. Disponible en: www. leymann.se [visitado el 11/07/2013].

López Perán, Andrés (2012): "El autodespido como mecanismo de tutela frente a las conductas de acoso laboral", en: Revista Estudios Laborales de la Sociedad Chilena de Derecho del Trabajo y de la Seguridad Social ( $\left.N^{\circ} 7\right)$, pp. 203-233.

Mangarell, Cristina (2008): "El acoso en las relaciones laborales", en: Revista Estudios Laborales de la Sociedad Chilena de Derecho del Trabajo y de la Seguridad Social (No 3), pp. 67-90.

Mekkı, Mustapha (2013): Vérité et preuve: rapport Français, Journées internationales de l'Association Henri Capitant, pp. 19-20. Disponible en: http://www. henricapitant.org/sites/default/files/France\%20(M.\%20Mekki).pdf [visitado el 21/07/2013].

Molina Navarrete, Cristóbal (2007): La tutela judicial frente al acoso moral en el trabajo: de las normas a las prácticas forenses (Granada, Editorial Bomarzo).

Palavecino Cáceres, Claudio (2004): "La protección contra el acoso psíquico laboral en el ordenamiento jurídico chileno", en: Revista de Derecho, Universidad Austral de Chile (Volumen 17), pp. 63-89.

PIÑUel, Iñaki (2005): Mobbing (Barcelona, Editorial Random House Mondadori).

Rodríguez Sanz de Galdeano, Beatriz (2011): "Las acciones de la persona acosada y de la acosadora. Acciones especiales", en: María Teresa Velasco Portero (directora), Mobbing, acoso laboral y acoso por razón de sexo, $2^{\text {a }}$ edición, (Madrid, Editorial Tecnos), pp. 111-140.

Romanik Foncea, Katy (2011): "El mobbing y su tratamiento en la legislación laboral", en: Informe de Actualidad Laboral de la Dirección del Trabajo (No 2), pp. 5-44.

Rubio de Medina, María Dolores (2011): “Los conceptos de acoso laboral (mobbing), acoso sexual y acoso por razón de sexo y su relación con la igualdad de oportunidades", en: María Teresa Velasco Portero (directora), Mobbing, acoso laboral y acoso por razón de sexo, $2^{\mathrm{a}}$ edición (Madrid, Editorial Tecnos), pp. 15-46.

Thauby DE LA Torre, Nicole (2012): Análisis conceptual y jurisprudencial de la indemnización de perjuicios como medida reparatoria del acoso moral o mobbing, Memoria para optar al grado de licenciada en Ciencias Jurídicas, Pontificia Universidad Católica de Valparaíso. 
UGARTE CATALDO, José Luis (2007): "La tutela de los derechos fundamentales y el Derecho del Trabajo: de erizo a zorro", en: Revista de Derecho, Universidad Austral de Chile (Volumen XX, No 2), pp. 49-67.

UGarte CATALDO, José Luis (2009 a): "Tutela laboral de derechos fundamentales y carga de la prueba", en: Revista de Derecho, Pontificia Universidad Católica de Valparaíso (Volumen XXXIII, Semestre II), pp. 215-228.

Ugarte CatalDo, José Luis (2009 b): Tutela de derechos fundamentales del trabajador (Santiago, Editorial Legal Publishing).

UGarte CATALDO, José Luis (2012): "El acoso laboral: entre el Derecho y la Psicología", en: Revista de Derecho, Pontificia Universidad Católica de Valparaíso (Volumen XXXIX, Semestre II), pp. 221-231. 